\title{
S-11-B-2b Effects of Granulocyte-Colony-Stimulating Factor in Neutropenic AIDS-Patients
}

\author{
F.-D.Goebel, J.R.Bogner, A.MAtuschke, \\ B.HEINRICH, and U.KRONAWITTER
}

Medizinische Poliklinik, Universität München, Pettenkoferstr. 8a, 8000 München 2, Germany

\section{INTRODUCTION}

Azidothymidin is the only antiviral substance, which has been demonstrated to increase the life span and reduce both incidence and complications of opportunistic infections in HIV-infected patients $(1,2,3)$. Gancyclovir (DHPG) treatment is required for cytomegalovirus induced disease (4). In both regimen neutropenia is the most common cause for cessation of therapy. Granulocytecolony-stimulating factor (G-CSF) increases the number of granulocytes by selective stimulation of the stem cells of the granulopoesis (5). We performed a placebo-controlled, dose-escalating study for AZT-induced neutropenia in 10 patients with G-CSF. Additional 6 patients were treated with G-CSF for DHPG-induced neutropenia on a compassionate use basis.

\section{II.STUDY DESIGN}

AIDS patients with a granulocyte count below $1000 / \mu 1$ were eligible. In the AZT group 2 patients each received placebo, $0.5,2.0,5.0,10.0 \mu \mathrm{g} / \mathrm{kg}$ G-CSF subcutaneously for 10 days. In the DHPG group patients received $5 \mu \mathrm{g} / \mathrm{kg}$ G-CSF for 6 up to 117 days (mean 44 days).

Values given in the text are means \pm standard deviation. Statistical analysis was performed by wilcoxon test.

\section{III, RESULTS}

Granulocytes increased in all patients treated with G-CSF at least to levels allowing continuation of the basic therapy without dose reduction. In the AZT group no significant change was seen under placebo. Eight hours after the first injection of G-CSF, the mean granulocyte count had increased from $997 \pm$ $186 / \mu 1$ before the injection to $3811 \pm 2205 / \mu 1(p<0.025)$ in the 
AZT-group. The mean maximum of the granulocyte count reached two peaks. In all but one patient the first peak occured on day 3 or 4 ; the second peak was reached between day 8 to 10 and appeared to be higher than the first one. The increase of granulocytes on the day after the first injection appeared not to be dose dependent, but the maximum increment of the granulocyte count showed a clear cut dose dependancy (figure 1). G-CSF was received in two batches for 5 patients each. There was a remarkable difference in the granulocyte increase between those two batches (figure 2). Two days after G-CSF was stopped the number of granulocytes started to decline. Within 2 weeks after discontinuation 3 of $8 \mathrm{AzT}$ patients had granulocyte count below $1000 / \mu 1$. Treatment with AZT had to be discontinued in 5 patients within 4 days after G-CSF was stopped.

In the DHPG group the mean granulocytes increased from $654 \pm$ $260 / \mu 1$ before the first injection to $2169 \pm 1480 / \mu 1$ one day later.

The lymphocyte subsets and serum neopterin levels were not affected by G-CSF. In 7 patients treated with G-CSF and AZT p24 antigen was detectable. In 6 of them p24 antigen levels increased from $26 \pm 23 \mathrm{pg} / \mathrm{ml}$ at entry to $33 \pm 29 \mathrm{pg} / \mathrm{ml}$ on day 11 in the avarage. In 1 patient the p24 antigen decreased from $3.4 \mathrm{pg} / \mathrm{ml}$ to $1.4 \mathrm{pg} / \mathrm{ml}$.

Beta-2-microglobulin levels increased from $4.0 \pm 1.1 \mathrm{mg} / 1$ on day 1 to $5.5 \pm 2.3 \mathrm{mg} / 1$ on day $4(p<0.025)$ in the AZT group. Seven days after G-CSF was stopped beta-2-microglobulin levels had decreased to $3.7 \pm 1.1 \mathrm{mg} / 1$.

\section{IV.SIDE-EFFECTS}

A drop of thrombocytes was observed in all patients treated simultaneously with G-CSF and AZT. On day 1 the mean platelet count was $164 \pm 60 \times 10^{3} / \mu 1$. Platelets started to decline on day 2 and reached the minimum between day 11 and 14 . The mean minimum was $100 \pm 48 \times 10^{3} / \mu 1$. Platelets decreased between $17 \%$ and $56 \%$ of the basic value. The decrease was not related to the dose of G-CSF. In contrast, only 2 of the 6 patients treated with G-CSF and DHPG developed a decline of the platelets, 
whereas the mean of the minimum of the platelet count of all six patients even increased.

One patient of G-CSF and AZT experienced a skin rash after 4 days, not reappearing on rechallenge on day 7 . No further adverse reactions were observed.

\section{CONCLUSIONS}

G-CSF appears to be valuable substance in AIDS patients with neutropenia. However, it should be considered with caution in AIDS patients with thrombocytopenia. The efficacy of long term treatment remains to be determined.

Even strongly myelotoxic drugs can be administered, if necessary, when G-CSF is available. The influence of G-CSF on HIV-replication in vivo has to be elucidated.

Our preliminary results emphasize the need for additional studies with G-CSF in AIDS patients with neutropenia for various reasons.

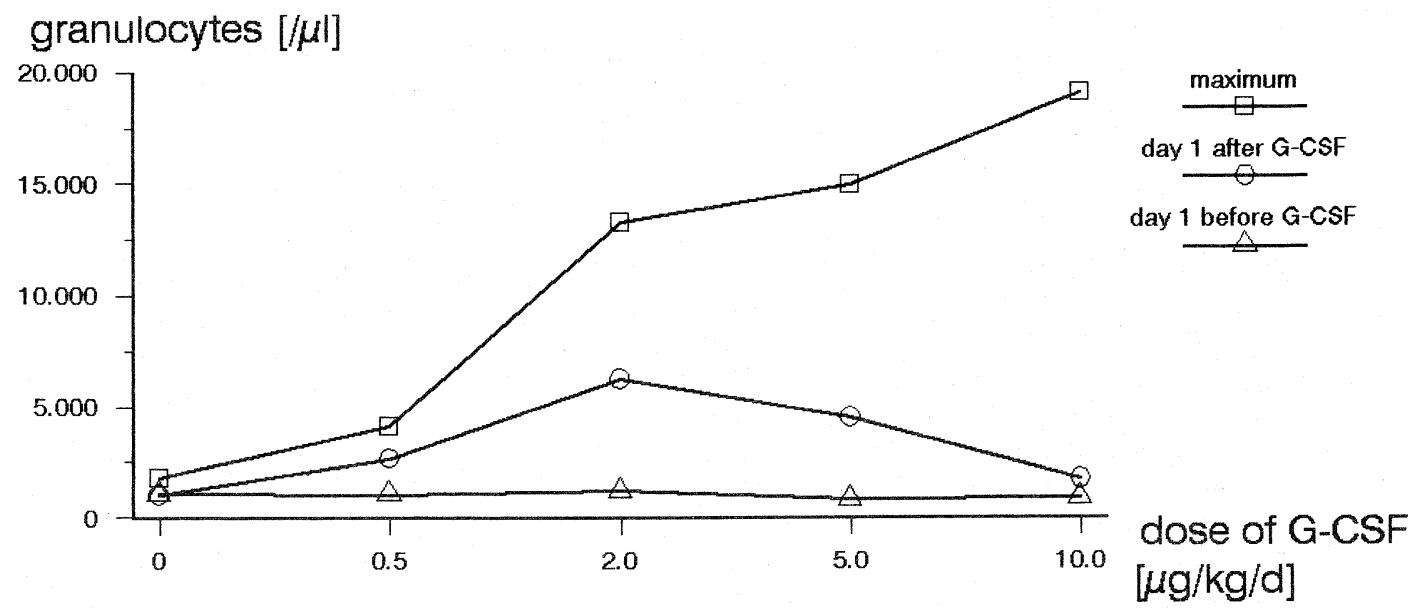

2 patients each received the same dose of G-CSF

Figure 1: Effects of the dose of G-CSF administered on the granulocyte counts in AIDS patients treated with zidovudine. 


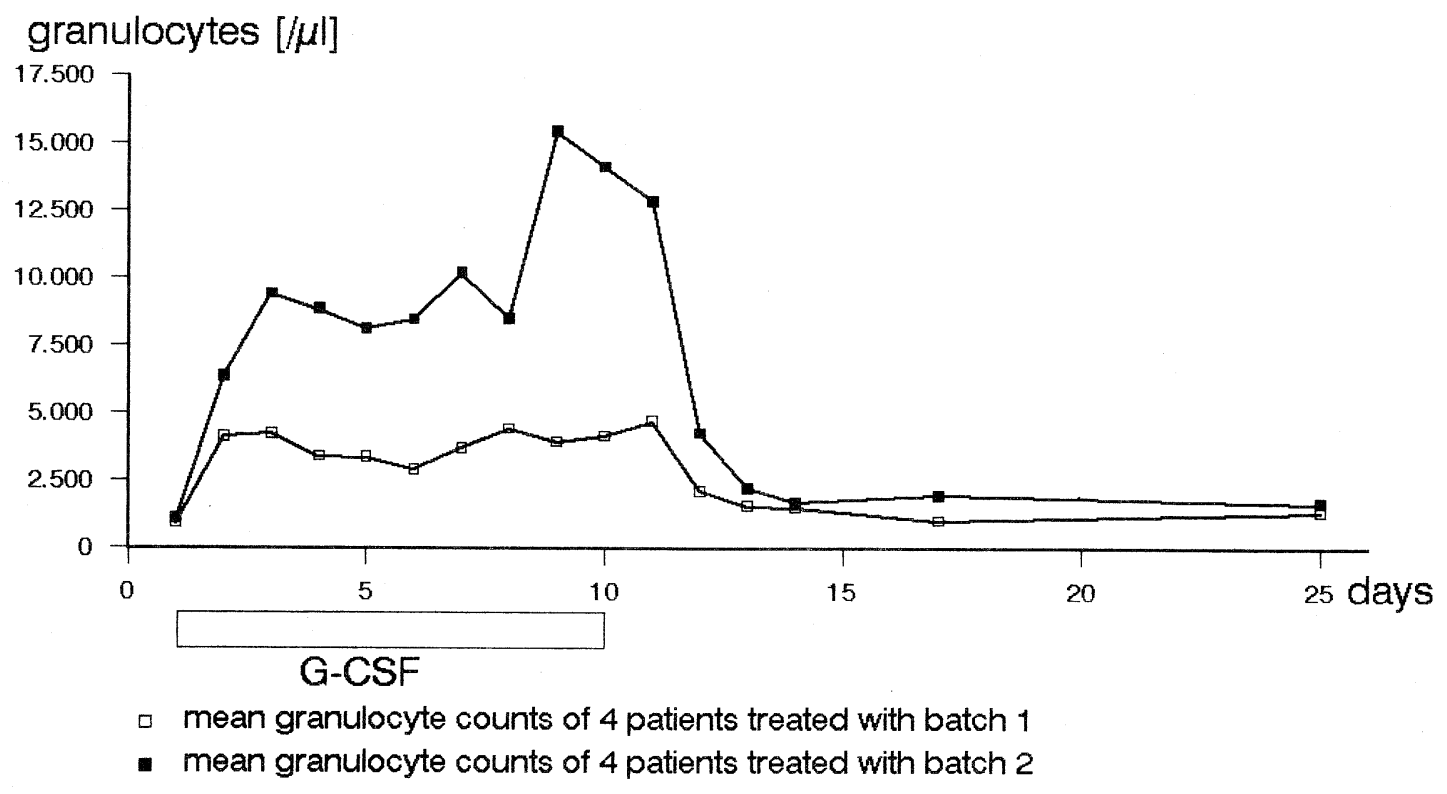

Figure 2: Effects of two different batches of G-CSF on the granulocyte counts in AIDS-patients on Zidovudine.

\section{REFERENCES}

1. Fischl MA et al.(1990): A radomized controlled trial of a reduced daily dose of zidovudine in patients with the acquired immunodeficiency syndrome. N.Engl.Med., 323: 1009-14.

2. Fischl MA et al.(1989): Prolonged zidovudine therapy in patients with AIDS and advanced AIDS-related complex. JAMA, 262: 2405-10

3. Volberding PA et al. (1990): Zidovudine in asymptomatic human immunodeficiency virus infection. N.Engl.J.Med.,322: 941-9.

4. Laskin, O.L. et al. (1987): Use of ganciclovir to treat serious cytomegalovirusinfections in patients with AIDS. J.Infect.Dis. 155: 323-7

5. Groopman JE et al. (1990): Hematopoietic growth factors: biology and clinical applications. N.Engl.J.Med., 321:1449-59 